of this rubber-working equipment is provided with auxiliary apparatus for controlling and recording temperatures, pressures and power consumption. The laboratory rooms are unique in that any of fifteen different services including electric power, air pressure, vacuum, hot and cold water, hydrogen, oxygen and nitrogen in addition to illuminating gas are available at any bench or can easily be made so. To improve the desirable characteristics of a rubber material and suppress the undesirable ones the rubber research organization endeavours to relete the physical characteristics of elastic materials to their molecular structure. Special apparatus is used in studying what happens to the rubber molecules when they are compounded, vulcanized, and destroyed through use. These studies on the mechanism of vulcenization, viscosity, molecular weight and brittleness of rubber and allied substances are associated with current synthetic rubber problems.

\section{Photography of Stars in Daylight}

MANY years ago it was predicted that stars close to the sun should be visible to an observer using a suitable technique. Only recently, however, has such a technique been developed, primarily for investigating the solar corona without waiting for a total eclipse. News has now reached Great Britain that a Swiss attempt to photograph stars in daylight with the aid of a coronagraph has been successful (M. Waldmeier, Z. Astrophys., 21, $269 ;$ 1942). A photograph obtained at Arcsa, at an altitude of 2,050 m. in the Alps, shows Regulus (mag. 1 34) quite clearly at a distance of $12^{\prime}$ (less than the sun's angular radius) from the edge of the solar disk. The observation is possible only by eliminating so far as possible diffracted and diffused light in the apparatus, and by observing at a great altitude to avoid meteorological scattering. The successful photograph was obtained at midday on August 22, 1941, with a 15-sec. exposure through a red filter. Regulus is the only firstmagnitude star within $1^{\circ}$ of the ecliptic, but there are a number of fainter stars (down to third magnitude) which, it is considered, could be photographed in favourable conditions.

One obvious application of the method is to the measurement of the gravitational deflexion of light. The Einstein effect has been observed at several eclipses since 1919 at considerable expense and with many disappointments, and the results have not been all that could be desired. The coronagraph method, if it can be developed so that precision. measurements are possible (at present the objective is an uncorrected single lens, though the field which must be covered is at least $1^{\circ}$ in diameter), will have many advantages. Accidental errors could be considerably reduced by multiplication of observations, for example, and the photographs would be taken under favourable working conditions at an established observatory instead of in the somewhat hectic circumstances of a total eclipse.

\section{Health of New Zealand}

Is his annual report for 1941-42, Dr. M. H. Watt, the director-general of health of New Zealand, states that during this period cerebrospinal fever has become epidemic on a small scale, as is shown by the fact that in the whole country there were 163 cases with 25 deaths among 1,538,620 Europeans, while there were 47 deaths among about 87,000 Maoris. It was found that the meningococcus was widespread among the employees at a freezing company, which suggested that the effect of the intense cold on the nasal mucous membrane lowered the local resistance so as to allow penetration of the organism. Of recent years there has been a considerable increase in known syphilis throughout New Zealand, the number of cases treated at the clinies being $156,192,285$ and 403 during the last four years. There has also been a sharp rise in notification of males suffering from tuberculosis, similar to that found in all the Allied countries and attributable to the special methods employed in the examination of recruits. As regards vital statistics, the birth-rate in Europeans was 22.81 and the deathrate $9 \cdot 81$, while in Maoris these rates were $44 \cdot 77$ and 20.59 respectively. The infant mortality of the Maoris was 125.06 as compared with the European rate of $29 \cdot 74$.

\section{Sudden Rise in Birth-Rate in the United States}

According to an editorial in the January issue of the Statistical Bulletin, the organ of the Metropolitan Life Insurance Company of New York, fairly complete data for 1942 for five large cities in the United States, namely, New York, Boston, Baltimore, Washington, D.C., and New Orleans, show not only that the general level of births for 1942 is materially higher but also that the profile of the curve is completely changed. Instead of a spring and a summer maximum there was a strong upward movement of births beginning about September and continuing almost unbroken to the end of the year. Moreover the level for the entire year is far above that of the period 1938-1939. The sudden increase in births in September and October 1942 would seem to be connected with the outbreak of war in December of the previous year.

\section{Recent Earthquakes}

The United States Coast and Geodetic Survey, in co-operation with Science Service and the Jesuit Seismological Association, has determined the epicentres of three recent earthquakes. The first occurred on March 7 at $3 \mathrm{~h}$. $01.5 \mathrm{~m}$. U.T. from an epicentre situated $57^{\circ} \mathrm{N}$. lat., $164^{\circ} \mathrm{E}$. long. This is in the Pacific Ocean near the east coast of central Kamchatka Peninsula. The second and third were both on March 9, at 3h. 25m. 32s. and 9h. 48m. 37s. U.r. respectively. The first on March 9 was from latitude $42.2^{\circ} \mathrm{N}$, longitude $80.9^{\circ} \mathrm{W}$., which is in the bed of Lake Erie to the west of Erie (city) and north-northeast of the city of Cleveland, and the second on March 9 from an epicentre at latitude $56^{\circ} \mathrm{S}$., longitude $22^{\circ} \mathrm{W}$., which is in the south Atlantic east of the island of South Georgia. All interpretations and calculations are tentative.

\section{Announcements}

AT the recent annual meeting of the Genetical Society the following officers were elected : President, Dr. C. D. Darlington; Vice-Presidents, Dr. R. N. Salaman, Prof. T. J. Jenkin, Prof. R. A. Fisher; Treasurer, Miss E. R. Saunders; Secretaries, Mr. E. B. Ford, University Museum, Oxford; Mr. W. J. C. Lawrence, John Innes Horticultural Institution, Merton, S.W.19.

Erratum.--In the News and Views "Announcements" in NATure of July 10 , we regret that w $\theta$ announced Dr. R. R. Mimms as being appointed lecturer in physies in the University of Birmingham. This is incorrect; for Dr. R. R. Mimms read Dr. R. R. Nimmo. 